\title{
CLIMATIC AND NON-CLIMATIC INFLUENCE ON FOOD GRAINS PRODUCTION- EMPIRICAL EVIDENCE FROM INDIAN AGRICULTURE
}

\author{
Shadman Zafar and DastagirAlam* \\ Department of Economics, Aligarh Muslim University, Aligarh, Uttar Pradesh, India \\ Zafar Iqubal \\ Department of Economics, University of North Bengal, West Bengal, India \\ *Corresponding author
}

\begin{abstract}
The present study is an attempt to examine long-run equilibrium and to figure out the effects of various indicators related to climatic conditions as well as nonclimaticparameters on production of foodgrainsin India. The extant studies in Indian context analyse climatic impact on agriculture in isolation with non-climatic factors (i.e., primary inputs) that may lead to the problem of model misspecification. This study acknowledges the fact that foodgrains production is an outcome determined by both climatic and non-climatic factors and hence, we incorporateboth factors into the model. The present study uses timeseries data on annual basis from the year 1986 to 2017 by using ARDL method.The method of cointegration is also used in the study. Long run results show that area, irrigation, fertilisers consumption and annual rainfall have significant and positive impact whereas mean annual temperature has significant and negative impact on foodgrains production in India. The credit factor has positive impact but it is insignificant for the period under study. Among all the factors, temperature has maximum impact on foodgrains production and may be assumed as one of the main factor affecting the status of food-security in absence of any adaptation.By acknowledging the fact that adaptation is the need of the hour, efforts should be made to make Indian agriculture climate-smart.
\end{abstract}

Key words: Food grains Production, Climate, Non-Climatic Factors, ARDL, Timeseries, India.

Cite this Article: Shadman Zafar, DastagirAlam and Zafar Iqubal, Climatic and Nonclimatic Influence on Food grains Production- Empirical Evidence from Indian Agriculture, International Journal of Management, 11(12), 2020, pp. 2544-2557.

http://iaeme.com/Home/issue/IJM?Volume=11\&Issue=12 


\section{INTRODUCTION}

Today the world has accepted climate change as a major challenge for agricultural practices. While its repercussions are being faced everywhere, developing countries are being affected more by this global phenomenon (IMF, 2017). India being a developing nation is also suffering from the same.From 1970 to 2016 , there has been an increase of about $0.48^{0} \mathrm{C}$ temperature (annual average temperature). In the same period, average monsoon rainfall has declined by around $26 \mathrm{~mm}$ (Hari et al., 2018). It is also predicted that there will be a three to four degree Celsius rise in temperature by the end of twenty-first century in India (Pathak et al., 2012). This phenomenon has serious implication for agricultural sector because climate directly affects physiology, morphology and phrenology of plants. Besides, they affect soil fertility, irrigation availability and may bring extreme climatic conditions in form of floods and droughts, that may lead to negative effect on the ability to produce agricultural output. Large body of research suggests that temperature and precipitation are the major climatic factors that have significant bearings on agriculture. It has been predicted that average farm income is likely to fall by $12 \%$ in absence of any adaptations to climate change (Government of India, 2018). Michael Oppenheimer co-authored in $5^{\text {th }}$ report of IPCC (Inter-governmental Panel on Climate Change) said, "Climate change is acting as a brake. We need yields to grow to meet growing demand, but already climate change is slowing those yields"(The Guardian, 2014). It is a matter of serious concern for developing countries where foodgrainsdemand is increasing because of the rise in population. Further, declining yield can be a cause of concern for food security in the years to come. Although application of chemical fertilizers, adequate irrigation and HYV seeds are likely to improve yield through resource-use efficiency, however, influences of climatic factors like low rainfall and rise in annual average temperature is believed to have a dent on the level of productivity.

The agricultural sector has always remain in a central discourse because this sector besides providing food to the public at large, also offers significant employment, inputs to industries, stabilize prices and is further crucial for inclusive growth than any other sector (Virmani, 2008). However, the sector does not reflect a similar and consistent pattern of growth throughout. Initially, area expansion and institutional reforms were the main drivers of growth in agricultural sector in the period followed by the independence (Rao, 2003). The pace of agricultural growth soon decelerated in early 1960s revealing that the area expansion has limited scope in raising agricultural production. During mid 1960s food grains productivity jumped by using high yielding variety (HYV) seeds, adequate irrigation, chemical fertilizers and latest technology commonly known as "green revolution". Although it augmented the elasticity of yield with respect to inputs considerably, but supply of credit to this sector were not enough. Hence, during 1980s India adopted multi-agency approach (services offered through NABARD, Commercial banks, cooperative banks and RRBs) to mitigate financial constraints in agricultural investment. Further, 1990s re-experienced sharp fall in this sector mainly due to factors like "technology fatigue", decline in state expenditure on irrigation and research activities, inadequate agricultural extension system and so on (Bhalla and Singh, 2009). The problem of downswing has further been exacerbated by the factors like climate change (Chand and Prappurathu, 2012).

In literature, primary inputs such as irrigation, fertilizers and seeds are the major determinants of agricultural output (Chand and Prappurathu, 2012; Kumar and Sharma, 2013; Tripathi and Prasad, 2009). When climate change becomes a pertinent issue, researchers starts modelling climatic factors with agricultural production/productivity and find an inverse relationship (Ahmed et al., 2016; Dell et al., 2012, 2014; Edame et al., 2011; Gadgil, 1995; Gupta et al., 2014; Kumar et al., 2016). Hence, there is increasing focus of economic research on the concerns related to climatic effect on agriculture in developing nations because of the 
fact that adverse climatic impacts on agriculture are more pronounced in hotter and less richer parts of the world (Dell et al., 2012, 2014; IMF, 2017).

A small but growing amount of research reveals the effect of climatic factors on various economic activities including agriculture (Burke et al., 2015; Dell et al., 2012; IMF, 2017). So why to reinvent the wheel? The answer is many folds. First, most of these are cross-country analysis that may not be relevant for a single country which is large, developing and climatically diverse like India. Second, in India where substantial population are food-insecure so the production of foodgrains assumes relatively greater importance than overall agricultural output. Also, foodgrains is assigned maximum area under cultivation and absorbs maximum workforce within agricultural sector in India. This necessitates a separate study that can explain the effects of climatic conditions on production of foodgrains. Third, the fact is that the determinants of food grains production are synthesis of climatic as well as non-climatic factors and hence, any analysis that considers climatic factors in isolation with non-climatic factors may create model misspecification problem. The present study is an attempt to incorporate both factors together and aims at answering questions as to whether climate significantly affects foodgrains production or not. The entire paper is divided into five sections. A brief review of literature is presented in the second section. The third section is all about methodology. Fourth section is given to data analysis and discussions. The last section concludes.

\section{BRIEF REVIEW OF LITERATURE}

The relationship between agriculture and its determining variables including climate has been extensively studied in literature. Largely there are two strands of literatures exist in this context. One is experimentally established simulation studies led by agricultural scientists like Mall and Aggarwal (2002), Pathak et al. (2003), Saseendran et al. (2000), Srivastava et al. (2010) and so on.It was suggested by Mall and Aggarwal (2000) that the results provided by the simulation models are appropriate for decisions related to crop management and to providing alternative options for the farming system. However, crop-simulation models are not directly relevant for economics literature. Second strand of literature is field based studies conducted by social scientists and economists like Kumar (1998), Kumar and Kavi (2009), Sanghi et al. (1998) and others. In this setting, most of the studies which relates climate change with agriculture adopted Ricardian approach (due to Mendelsohn et al., 1994) which uses farm level net revenue as dependent variable. According to Kumar (2009) a sufficient amount of research based on Ricardian analysis has calculated that temperature rise and variability in rainfall leads to decline in net farm revenue.

At district level, the studies of Fishman (2011), Guiteras (2009), and Krishnamurthy (2012) is noteworthy. Guiteras (2009) quantifies the impact on agricultural output of random year-toyear variation in weather by incorporating farmers' within-year adaptation to weather-shocks in India. The estimates resulting from short-run weather effects are used to project medium-run and long-run impacts. The study forecasts that the climate change during2010 to 2039 (mediumrun) may reduce the yield of major cropsranging between 4.5 to 9 percent and in the long run for the period of 2077 to 2099 by $25 \%$ in absence of long-run adaptations. It clearly indicates that in absence of any adaptation to climate change will impose substantial costs on Indian economy. He further maintained that such quick adaptation is less probable in developing countries experiencing lack of information and capital. Fishman (2011) worked on intraseasonal rainfall variability on yields argued that the effects can be diluted by the adaptations (such as irrigation) which however is limited by ground water depletion.

At state level, Kanwar (2006) calculated supply response and found that rainfall is a significant shift factor. While estimating the impact of very low or very highprecipitation on rice yields, Auffhammer et al. (2012) also found significant impacts. Hundal et al. (2007) 
mentioned that rise in minimum temperature up to one to three degree celcius above normal resulted into productivity fall in case of rice by $3 \%$ and wheat by $10 \%$ in the state of Punjab. While Sushila and Ghasi (2009) found adverse effect in Jowar productivity in Karnataka, Geetalakshmi et al. (2011) and Saseendran et al. (2000) found decline in rice productivity in Tamil Nadu and Kerela respectively.

At all India level, Kumar et al. (2014) observed the effects of climatic and nonclimatic indicators on the production of sugarcane. He used three important models namely; Simple linear regression, Cobb-Douglas production function and Ricardian productivity non-linear regression model. It was found that climatic variables have significant impact on the productivity of sugarcane. To assess the effect of climate change on agricultural productivity Kumar and Sharma (2013) used the data for a period of 1980 to 2009 and found that agricultural productivity is very much affected by climate change and has negative effect on food security in India. A similar study done by Kumar et. al. (2016) reveals the negative effect of climate change on productivity level of both foodgrains and nonfoodgrains crops. This study was based on the data received from 13 states for the period of 1980 to 2009. A study conducted by Lahiri and Roy (1985) exposed that floods are less harmful than droughts with respect to yield of rice.

David Boansi (2017) studied the behaviour of climatic and nonclimatic indicators for Togo regions and reached to the conclusion that Cassava yield is affected by these variables. Terence et al. (2018) with the objective to find out the determinants of crop yield in Uganda categorised determining variables into climatic and nonclimatic indicators and applied two-stage multiple regression model. They find that non-climatic drivers (forest area dynamics, wood fuel, usage of tractors) are more important than climatic factors (precipitation, $\mathrm{CO} 2$ emission, temperature).

This study is different from others in two ways. Firstly, the extant strand of literature related to the present study is either crop-specific or focused on overall agricultural output. However, general masses in India are more concerned with foodgrains production because it is directly linked with the sustainability of overall agricultural production, food-security and povertystatus of common people. Second, most of the studies discussed above look at the effects of climatic indicators on agriculture in isolation with nonclimatic indicators (i.e., primary inputs like irrigation, fertilizers and credit etc). The fact that both factors together determine the quantum of foodgrains production in India paves the way for adding non-climatic variables into the model. Though few studies were done by incorporating both the factors in case of India, but they are crop-specific (like Kumar et al., 2014). The present study makes an attempt to analyse the effects of climatic as well as non-climatic indicators on foodgrains production in India. For the present research endeavour, ARDL approach to co-integration is being used.

\section{DATA \& METHODOLOGY}

Economic theory identifying various factors that influence foodgrains production can be put under two broad categories namely climatic and nonclimatic indicators. This study considers two climatic factors- annual rainfall and mean annual temperature and four non-climatic factors- area under cultivation, area under irrigation, consumption of fertilizers and amount of credit.

The hypothesized long-run relationship between foodgrains production, rainfall, temperature, area, irrigation, fertilizers and credit in lin-log form is as follows:

$$
\begin{gathered}
F G P R O D_{t}=\beta_{0}+\beta_{1} A R E A_{t}+\beta_{2} A U I_{t}+\beta_{3} F E R T_{t}+\beta_{4} L N C R E D_{t}+\beta_{5} R_{A I N}+ \\
\beta_{6} \text { TEMP }_{t}+\epsilon_{t}
\end{gathered}
$$

where' $\epsilon$ ' and ' $t$ ' represents error term and time respectively. FGPROD refers to amount of foodgrains production expressed in million tonnes which includes rice, wheat, coarse cereals 
Climatic and Non-climatic Influence on Food grains Production- Empirical Evidence from Indian Agriculture

and pulses. AREA refers to area under cultivation of food grains expressed in million hectares, AUI refers to area under irrigation expressed as percentage of gross cropped area, FERT represents consumption of fertilizers $(\mathrm{N}+\mathrm{P}+\mathrm{K})$ expressed in million tonnes, LNCRED denotes log of flow of credit (institutional) to agriculture sector by multi agencies (commercial banks + cooperative societies + RRBs) expressed in crores, RAIN refers to amount of annual rainfall in $\mathrm{mm}$ and TEMP refers to mean annual temperature in degree Celsius. Figure 1 given below represents the movement of the variables over the period under study.

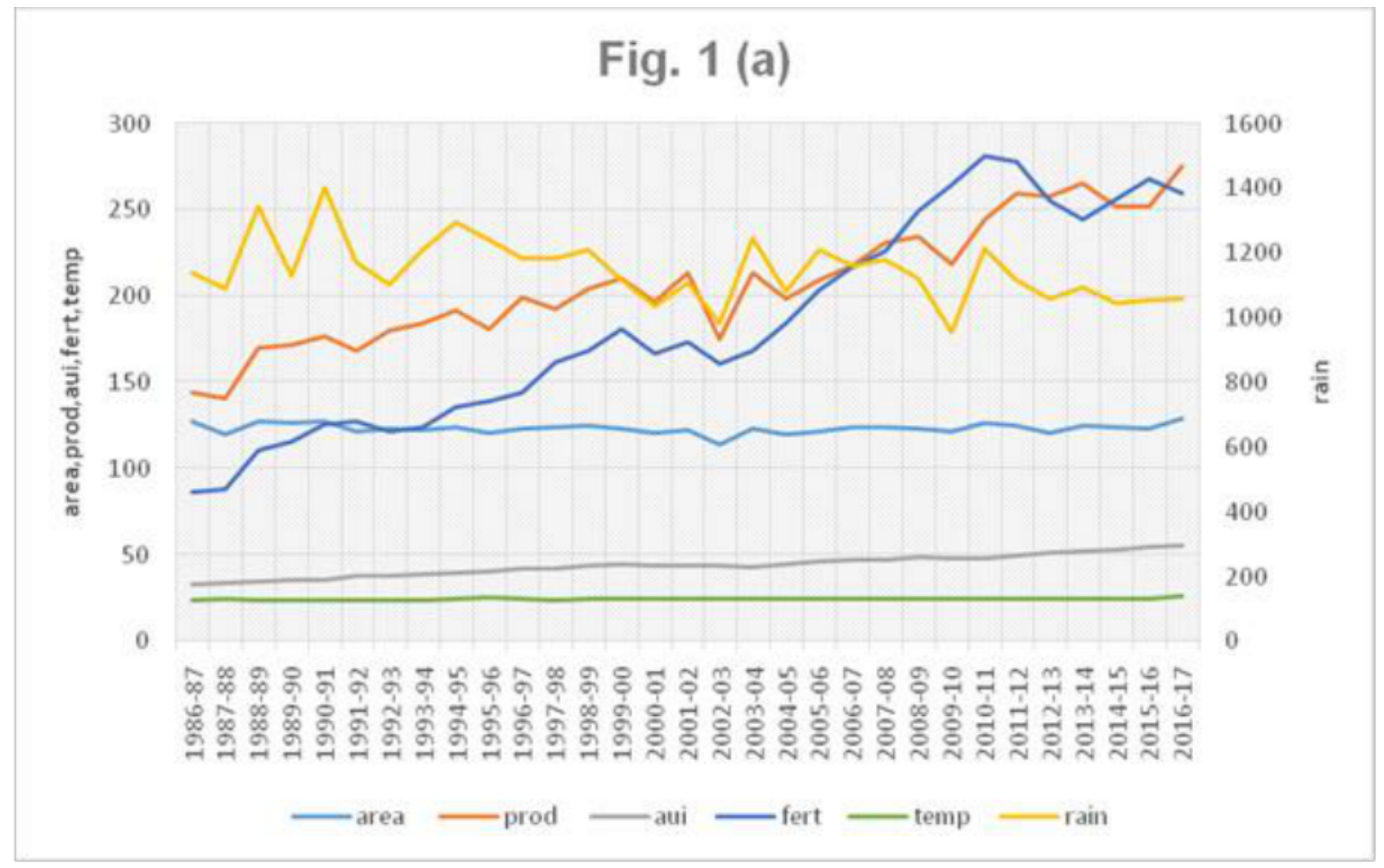

Fig. 1 (b)

1200000

1000000

800000

壱 600000

400000

200000

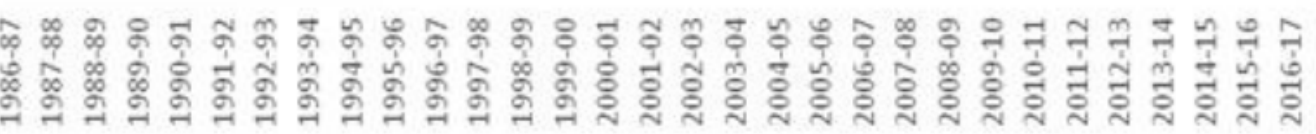

Figure 1 Movement of variables over time

Note: All the variables are taken on the primary axis except rainfall which is taken on secondary axis 


\subsection{Data set}

The study covers the sample period from 1986-87 to 2016-17. The last two years data for area under irrigation is extrapolated due to its unavailability. Data on foodgrains production, area, irrigation, fertilizer and credit are taken from Ministry of Agriculture. The data for rainfall and temperature is collected from Indian Meteorological Department (IMD database).

\subsection{Model Specification}

Equation (1) can be estimated by using any method of cointegration. The study is based on Pesaran and Shin's (1998) ARDL model. The advantage of ARDL lies in its relaxability in allowing for $\mathrm{I}(0)$ and $\mathrm{I}(1)$ variables and its relevancy in case of small sample size. However, the model cannot be applied in case any variable in the model is integrated of second order because in such case it produces invalid F-statistics (Ouattara, 2014). In order to check the stationarity of data, Augmented Dickey-Fuller test (null is non-stationary) is used. Wiatkowski-PhillipsSchmidt-Shin test (null is stationary) is used to check the order of integration of the variables.

The ARDL procedure involves the estimation of following equation:

$$
\begin{aligned}
\triangle F G P R O D_{t}= & \alpha_{0}+\sum_{i=1}^{p} \alpha_{1 i} \Delta F G P R O D_{t-i}+\sum_{i=0}^{p} \alpha_{2 i} \Delta A R E A_{t-i} \sum_{i=0}^{p} \alpha_{3 i} \Delta A U I_{t-i} \\
& +\sum_{i=0}^{p} \alpha_{4 i} \Delta F E R T_{t-i}+\sum_{i=0}^{p} \alpha_{5 i} \Delta L N C R E D_{t-i}+\sum_{i=0}^{p} \alpha_{6 i} \Delta R A I N_{t-i} \\
& +\sum_{i=0}^{p} \alpha_{7 i} \Delta \text { TEMP }_{\mathrm{t}-\mathrm{i}}+\theta_{1} \text { FGPROD }_{\mathrm{t}-1}+\theta_{2} \text { AREA }_{\mathrm{t}-1}+\theta_{3} \text { AUI }_{\mathrm{t}-1} \\
& +\boldsymbol{\theta}_{4} \text { FERT }_{\mathrm{t}-1}+\boldsymbol{\theta}_{5} \text { LNCRED }_{\mathrm{t}-1}+\boldsymbol{\theta}_{6} \text { RAIN }_{\mathrm{t}-1}+\boldsymbol{\theta}_{7} \text { TEMP }_{\mathrm{t}-1} \\
& +\mu_{\mathrm{t}}
\end{aligned}
$$

Where $\Delta$ stands for the first difference operator, $\boldsymbol{\alpha}_{\mathbf{0}}$ is intercept, $\boldsymbol{\mu}_{\mathbf{t}}$ is random error assuming it to be white noise process and the variables FGPROD, AREA, AUI, FERT, LNCRED, RAIN and TEMP are already defined, the expression with summation signs $\left(\alpha_{1 i}-\alpha_{7 i}\right)$ represents the short-run coefficients of the model while the coefficients $\left(\theta_{1}-\theta_{7}\right)$ represent the long-run coefficients. The entire method involves two step procedures. The bound testing procedure is used here for knowing the long run relationship among the variables in the model. To test the null hypothesis of no cointegration $\left(\mathbf{H}_{0}: \boldsymbol{\theta}_{\mathbf{1}}=\boldsymbol{\theta}_{\mathbf{2}}=\boldsymbol{\theta}_{\mathbf{3}}=\boldsymbol{\theta}_{\mathbf{4}}=\boldsymbol{\theta}_{5}=\boldsymbol{\theta}_{6}=\boldsymbol{\theta}_{\mathbf{7}}=\mathbf{0}\right)$., joint F-statistics is used. There are two set of critical values for a given significance level (Narayan., 2005 and Pesaran et al. 2001). One assumes stationary at I(0) level while other assumes at first difference i.e., I(1). Here the null hypothesis will be rejected in case the upper critical bound value is less than computed test statistics. If computed test statistics is in between bounds the result is inconclusive that paves the way for error correction term to establish cointegration (Kremers et al., 1992 and Banerjee et al., 1998). If it is lower than the lower bounds value, it is difficult to reject the null hypothesis. After establishing cointegration, the long-run as well as short-run coefficients are estimated. Before the selected model is estimated, it is important to choose lag selection criteria. In a situation when the SIC method is better than AIC method, it is advisable to choose a maximum of two lags in case of annual data (Pesaran and Shin, 1998).

When we successfully established the long run relationship, error correction model can be applied with the following method: 


$$
\begin{aligned}
\Delta F G P R O D_{t}= & \alpha_{0}+\sum_{i=1}^{p} \alpha_{1 i} \Delta F G P R O D_{t-i}+\sum_{i=0}^{p} \alpha_{2 i} \Delta A R E A_{t-i}+\sum_{i=0}^{p} \alpha_{3 i} \Delta A U I_{t-i} \\
& +\sum_{i=0}^{p} \alpha_{4 i} \Delta F E R T_{t-i}+\sum_{i=0}^{p} \alpha_{5 i} \Delta L N C R E D_{t-i}+\sum_{i=0}^{p} \alpha_{6 i} \Delta R A I N_{t-i} \\
& +\sum_{i=0}^{p} \alpha_{7 i} \Delta \operatorname{TEMP}_{t-i}+\eta E C T_{-1} \\
& +\mu_{t}
\end{aligned}
$$

Here $\eta$ refers to the speed of adjustment every year towards equilibrium and $\mathrm{ECT}_{\mathrm{t}-1}$ is the residuals we get from Eq. (1). Further, Diagnostic test of the model are conducted. It checks for serial correlation of error terms, correct functional form, normally distributed errors and heteroscedasticity. The residual serial correlation (with no serial correlation as null hypothesis) can be checked with Lagrange Multiplier (LM) test. The correct functional form of the model can be checked with Ramsey's Reset test. Similarly the normality of random term can be test with the Jarque-Bera statistics. The presence of heteroscedasticity is tested by using BreuschPagan-Godfrey test (the null is homoscedastic). Finally, CUSUM (cumulative sum) and CUSUMSQ (cumulative sum of squares) check for the stability of the short-run and long run parameters (the null is all the parameters are stable) as suggested by Brown et al. (1975).

\section{EMPIRICAL RESULTS AND DISCUSSION}

In time series data, when a variable s non stationary we accept the presence of a unit root while its absence refers to stationarity of variable at level. One unit root means the variable under consideration is integrated of order one. Two unit root means the variable is integrated of order two and so on. The order of integration of the time series variable was investigated by applying the ADF test and KPSS test whose results are presented in table 1. The table shows that the variables in the model are stationary either at level or at first difference. No variable in the model is stationary at second difference or beyond that. This paves the way for application of ARDL model and lead us to bounds testing to co integration approach.

Table 1 Result ofunit root tests

\begin{tabular}{|llllc|}
\hline Variables & \multicolumn{2}{c}{ ADF (test-statistics) } & \multicolumn{2}{c|}{ KPSS (test-statistics) } \\
\hline & without trend & with trend & without trend & with trend \\
\hline FGPROD & -1.01 & $-4.61^{* * *}$ & $0.71^{* *}$ & 0.12 \\
\hline D(FGPROD) & $-10.06^{* * *}$ & $-9.89^{* * *}$ & $0.50^{* *}$ & $0.50^{* * *}$ \\
\hline AREA & $-5.17^{* * *}$ & $-4.97^{* * *}$ & 0.17 & $0.16^{* *}$ \\
\hline D(AREA) & $-5.74^{* * *}$ & $-5.77^{* * *}$ & 0.38 & $0.50^{* * *}$ \\
\hline AUI & -0.09 & 2.09 & $0.72^{* *}$ & 0.09 \\
\hline D(AUI) & $-5.75^{* * *}$ & $-5.66^{* * *}$ & 0.08 & 0.07 \\
\hline FERT & -1.01 & -2.43 & $0.69^{* *}$ & 0.06 \\
\hline D(FERT $)$ & $-3.94^{* * *}$ & $-3.93^{* *}$ & 0.08 & 0.07 \\
\hline LNCRED & 0.31 & -2.86 & $0.72^{* * *}$ & 0.14 \\
\hline D(LNCRED) & 0.31 & $-3.82^{* *}$ & 0.28 & $0.19 * *$ \\
\hline RAIN & -4.82 & $-6.59^{* * *}$ & $0.54 * *$ & 0.07 \\
\hline
\end{tabular}




\begin{tabular}{|lllll|}
\hline $\mathrm{D}(\mathrm{RAIN})$ & $-11.09 * * *$ & $-10.99 * * *$ & $0.50 * * *$ & $0.50 * * *$ \\
\hline TEMP & -1.83 & $-3.95 * *$ & $0.74 * * *$ & 0.11 \\
\hline $\mathrm{D}($ TEMP $)$ & $-5.09 * * *$ & $-5.09 * * *$ & 0.19 & 0.10 \\
\hline
\end{tabular}

Note: *** and ** shows rejection of null hypothesis (non-stationary for ADF-test and stationarity for KPSS-test) at $1 \%$ and 5\%significance levels respectively. Hence, presence of asterisk represents stationarity in ADF test while its absence represents stationarity in KPSS test. The optimal lag order for ADF test is determined by SIC (automatic selection) while for KPSS test by Newey-West bandwidth

\subsection{Cointegration Result}

The calculated value of F-statistics along with their critical values are reported in Table 2 . It gives an estimated value of 9.56. Here, the upper bound critical value is less than the estimated value and we can reject the null hypothesis which states that there is no cointegration. Since there exists a cointegration relationship among the variables at 1 per cent level of significance, long run relationship among the variables can be established.

Table 2 Result of cointegration test

\begin{tabular}{|l|ccc|}
\hline \multirow{2}{*}{$\begin{array}{l}\text { Level of } \\
\text { significance }\end{array}$} & Lower bound I(0) & Upper bound I(1) & F-value \\
\hline $10 \%$ & 1.99 & 2.94 \\
\hline $5 \%$ & 2.27 & 3.28 \\
\hline $2.5 \%$ & 2.55 & 3.61 & 9.56 \\
\hline $1 \%$ & 2.88 & 3.99 & \\
\hline
\end{tabular}

Note: $* * * * *$ and $*$ are significance at $1 \%, 5 \%$ and $10 \%$ levels respectively. Numbers in parentheses are p-values. Note: Critical lower and upper bound values are collected from Narayan (2005). The Fvalue is calculated at $\mathrm{T}=31$ and $\mathrm{K}=6$.

\subsection{Long-run and short-run coefficients}

Following the Schwarz Information Criteria (SIC) criteria, the long-run coefficients are estimated by using a maximum of one lag period. The estimated values of coefficients are reported in Table 3. A maximum of one lag period is used to lower down the loss of degrees of freedom.

Table 3 Result of long-run coefficients

\begin{tabular}{|l|l|}
\hline Long-run result & \\
\hline AREA & $1.86^{* * *}(0.0043)$ \\
\hline AUI & $3.98^{* * *}(0.0001)$ \\
\hline FERT & $1.85^{* *}(0.0416)$ \\
\hline LNCRED & $-0.07(0.9862)$ \\
\hline RAIN & $0.03^{*}(0.0867)$ \\
\hline TEMP & $-7.41 * * *(0.0179)$ \\
\hline CONSTANT & $-77.94 \quad(0.4598)$ \\
\hline
\end{tabular}

Note: $* * * * *$ and $*$ are significance at $1 \%, 5 \%$ and $10 \%$ levels respectively. Numbers in parentheses are $\mathrm{p}$-values 
Empirical results clearly say that all the explanatory variables are effective in determining the foodgrains production in India, except credit. All the variables other than credit and temperature exhibits positive relationship with foodgrains production. The possible reasons for credit showing negative and insignificant result could be the diversion of funds from productive purposes to self-consumption purpose that renders the credit ineffective in the long run to influence foodgrains production in India. A one million hectare increase in area under cultivation leads to 1.86 million tonnes increase in foodgrains production. Hence, bringing more area under cultivation can fetch more foodgrains however it has limited scope in raising foodgrains production because total physical area for an economy is limited and has multiple uses too. Therefore, productivity gains through use of chemical fertilizers and provision of water play crucial role. This study finds that consumption of chemical fertilizers has positive effects on foodgrains production. One million tonnes increase in fertilizers use leads to 1.85 million tonnes average increase in foodgrains production. Application of chemical fertilizers in the form of nitrogen $(\mathrm{N})$, phosphate $(\mathrm{P})$ and potash $(\mathrm{K})$ supplement their deficiency in soils and increases potential to produce, if $\mathrm{N}: \mathrm{P}: \mathrm{K}$ is combined optimally. Further, water is an indispensable resource for agriculture which is primarily provided naturally through rainfall. However, it is often associated with inadequate, irregular and untimely provision of water to the field and hence its effect on the quantum of foodgrains production though significant but minimal vis-à-vis other factors. This study reveals that if average amount of rainfall in India increases by one $\mathrm{mm}$, foodgrains production on an average increase by 0.03 million tonnes only. The monsoon-dependency and associated uncertainties compels an economy to deliver enough and timely irrigation services. As a result, more than 50 percent of the gross cropped area in India is irrigated. In the present study, irrigation is the most effective positive contributor among non-climatic factors. A one percent increase in area under irrigation causes foodgrains production to significantly increase by 3.98 million tonnes. It corroborates the study of Bhattarai et al. (2004), Dhawan (1988), Jin et al. (2012), Vaidyanathan (1987) and others. Adequate irrigation facilitates regular and timely provision of water to the field, ensures sufficient moisture to the soil and after combining with chemical fertilizers eventually enhances efficiency of production.

Among all the variables and particularly amongst climatic factors, temperature has maximum impact. The extreme temperature during some crucial months may disturb soilmoisture and can adversely affect specific crops. The result is consistent with various other studies on climate change in India (Gadgil et al., 1995; Guiteras, 2009; Gupta, 2014; Hari et al., 2018; Kumar, 2016; Lahiri and Rai, 1985). The rise in mean annual temperature by one degree Celsius will decrease average production of food grains by 7.41 million tonnes. This may have negative effect in realising the goal of food-security in absence of any adaptation and the defined 67 percent population coverage under national food security act cannot be ensured on sustained basis.

Table 4 provides information about the short run analysis of ARDL model along with error correction term. The short-run results have similar interpretation for all variables except fertilizer. The negative coefficient value for fertilizer $\mathrm{n}$ short run may be a result of farmers' ignorance because of which farmers might be combining NPK fertilizers in inappropriate proportion. But they are able to learn from mistakes and manage to have positive effect of fertilizer in the long run. The value of error correction term is significantly high equal to -0.84 . this shows that short run disturbances are immediately corrected in a less than one year. 
Table 4 Result of short-run coefficients

\begin{tabular}{|l|l|}
\hline Short-run result & \\
\hline D(AREA) & $2.80 * * *(0.0000)$ \\
\hline D(AUI) & $5.72 * * *(0.0000)$ \\
\hline D(FERT) & $-2.63 * * *(0.0051)$ \\
\hline D(LNCRED) & $-5.59(0.3806)$ \\
\hline D(RAIN) & $0.01 *(0.0586)$ \\
\hline D(TEMP) & $-6.03 * * *(0.0055)$ \\
\hline ECT $(-1)$ & $-0.84 * * *(0.0000)$ \\
\hline
\end{tabular}

Note: $* * *, * *$ and $*$ are significance at $1 \%, 5 \%$ and $10 \%$ levels respectively. Numbers in parentheses are p-values

\subsection{Diagnostic Checking and Stability-test}

The results reported in Table 5 demonstrate that the model satisfies the diagnostic tests. Errors are normally distributed whose variance are constant over time. There is no evidence of serial correlation up to lag 1 . Ramsey reset test for model stability validates the functional form at $5 \%$ level. Hence, all tests validate that the model has desired econometric properties. The graph represented below in Figures 2 indicates that the plot of both CUSUM and CUSUMSQ lie within boundaries that prove the stability of all the parameters. Therefore, the model is properly specified and stable.

Table 5 Result of diagnostic test of the model

\begin{tabular}{|lllcccc|}
\hline $\begin{array}{l}\text { Diagnostic } \\
\text { test }\end{array}$ & Adj. $\mathbf{R}^{2}$ & LM & JB & BPG & Ramsey & CUSUM \\
Value & 0.92 & $\mathbf{0 . 0 7}$ & $\mathbf{0 . 7 6}$ & $\mathbf{0 . 8 1}$ & $\mathbf{0 . 3 9}$ & Stable \\
\hline
\end{tabular}

Note: LM test is for serial correlation. Ramsey's Reset is for functional form. Jarque-Bera statistics is for normality. Breusch-Pagan-Godfrey test is for heteroscedasticity. The figures in bold are p-value.
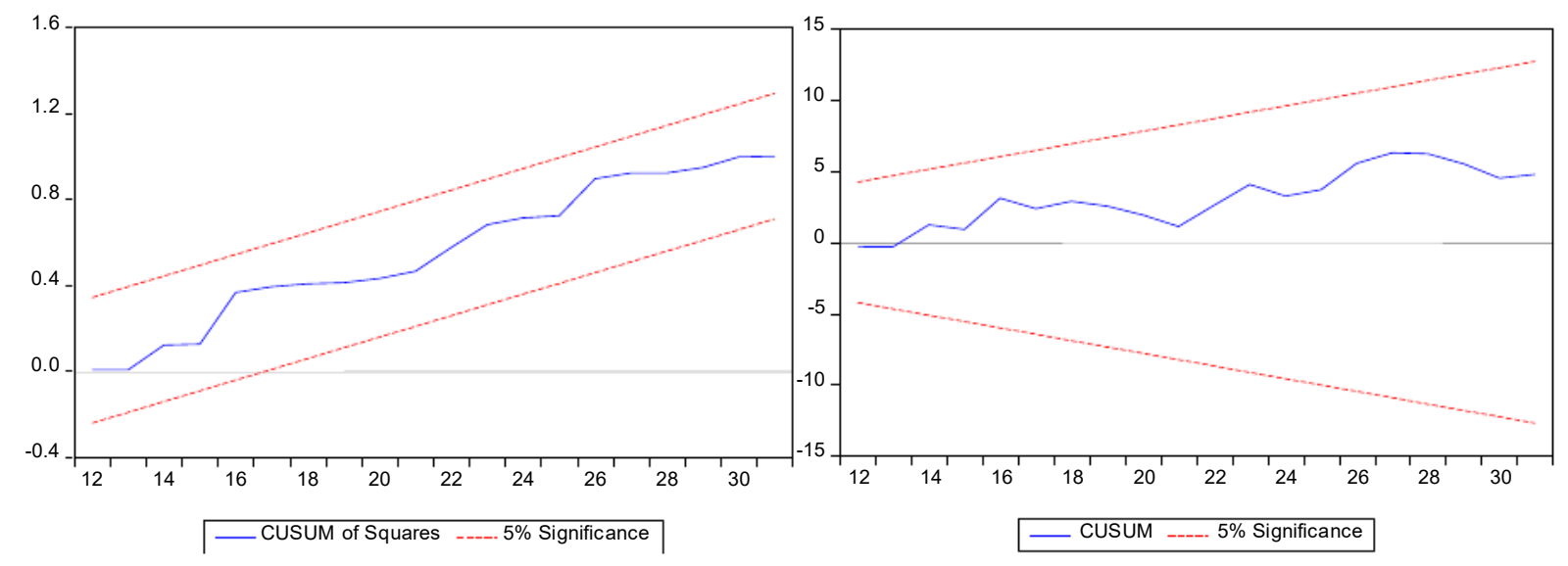

Figure 2 Graph of CUSUM and CUSUMSQ 


\section{CONCLUSION}

In order to look at the climatic effect in agricultural sector, existing studies either concentrated on specific crops or take overall agricultural production. However, for many people of this country who are deprived of food-security, production of food crops matters more than overall agricultural output (it includes several items like cash crops etc). Also, to the best of our knowledge, studies in India look at the climatic effects on agriculture in isolation with primary inputs like fertilizers, irrigation, credit etc.

In the study, bound testing approach to cointegration is used within autoregressive distributed lag framework for the period from 1986-87 to 2016-17. The result from ARDL indicates that there is a cointegration between foodgrains production and explanatory variables namely area, irrigation, fertilizers, rainfall and temperature. This relationship between dependent and independent variables of the model is very much effective in long run and any short run disturbances are very much able to be corrected in short run and leads to the conclusion of existence of long-run relationship. The results reveal that mean annual temperature has maximum effect on foodgrains production followed by irrigation. Area, fertilizers and rainfall also have positive contribution, but coefficient of rainfall is relatively low. Credit is insignificant for the period under study.

Thus, climatic factor is related to foodgrains production both directly as well as indirectly and hence makingof agricultural policies in India ignoring environmental factors will not yield good results. Agricultural practices should be made sustainable with the help of right farming practices such as organic farming, manure management, agro-forestry practice, drip irrigation, etc. By acknowledging the fact that adaptation is the need of the hour, Indian agriculture can be made climate-smart. The findings of the study not only have great policy implications but also serves academic interests.

\section{REFERENCES}

[1] Auffhammer, M., Ramanathan, V., \& Vincent, J. R. (2012). Climate change, the monsoon, and rice yield in India. Climatic change, 111(2), 411-424.

[2] Banerjee, A., Dolado, J., \&Mestre, R. (1998). Error-correction mechanism tests for cointegration in a single-equation framework. Journal of time series analysis, 19(3), 267-283.

[3] Bhalla, G. S., \& Singh, G. (2009). Economic liberalisation and Indian agriculture: a statewise analysis. Economic and Political Weekly, 34-44.

[4] Bhattarai, M., \&Narayanamoorthy, A. (2004). Impact of irrigation on agricultural growth and poverty alleviation: macro level analysis in India. Water policy research highlight, 12, 1-7.

[5] Boansi, D. (2017). Effect of climatic and non-climatic factors on cassava yields in Togo: Agricultural policy implications. Climate, 5(2), 28.

[6] Brown, R. L., Durbin, J., \& Evans, J. M. (1975). Techniques for testing the constancy of regression relationships over time. Journal of the Royal Statistical Society: Series B (Methodological), 37(2), 149-163.

[7] Burke, M., Hsiang, S. M., \& Miguel, E. (2015). Global non-linear effect of temperature on economic production. Nature, 527(7577), 235-239. 
[8] Dell, M., Jones, B. F., \&Olken, B. A. (2012). Temperature shocks and economic growth: Evidence from the last half century. American Economic Journal: Macroeconomics, 4(3), 6695 .

[9] Dell, M., Jones, B. F., \&Olken, B. A. (2014). What do we learn from the weather? The new climate-economy literature. Journal of Economic Literature, 52(3), 740-98.

[10] Edame, G. E., Ekpenyong, A. B., Fonta, W. M., \&Duru, E. J. C. (2011). Climate change, food security and agricultural productivity in Africa: Issues and policy directions. International journal of humanities and social science, 1(21), 205-223.

[11] Epule, T. E., Ford, J. D., Lwasa, S., Nabaasa, B., \&Buyinza, A. (2018). The determinants of crop yields in Uganda: what is the role of climatic and non-climatic factors?. Agriculture \& Food Security, 7(1), 10.

[12] Fishman, R. M. (2011). Climate change, rainfall variability, and adaptation through irrigation: Evidence from Indian agriculture. Job Market Paper.

[13] Gadgil, S. (1995). Climate change and agriculture-an Indian perspective. Current Science, 69(8), 649-659.

[14] Geethalakshmi, V., Lakshmanan, A., Rajalakshmi, D., Jagannathan, R., Sridhar, G., Ramaraj, A. P., \&Anbhazhagan, R. (2011). Climate change impact assessment and adaptation strategies to sustain rice production in Cauvery basin of Tamil Nadu. Current Science, 342-347.

[15] Goldenberg, S. (2014). Climate change a threat to security, food and humankind-IPCC report. The Guardian, 31.

[16] Government of India (2018), 'Economic Survey of India, 2017-18'

[17] Guiteras, R. (2009). The impact of climate change on Indian agriculture. Manuscript, Department of Economics, University of Maryland, College Park, Maryland.

[18] Gupta, S., Sen, P., \& Srinivasan, S. (2014). Impact of climate change on the Indian economy: Evidence from food grain yields. Climate Change Economics, 5(02), 1450001.

[19] Hari, S., Khare, P., \& Subramanian, A. Climate change and Indian agriculture.

[20] Horowitz, J. K. (2009). The income-temperature relationship in a cross-section of countries and its implications for predicting the effects of global warming. Environmental and Resource economics, 44(4), 475-493.

[21] Hundal, S. S. (2007). Climatic variability and its impact on cereal productivity in Indian Punjab. Current Science, 506-512.

[22] IMF (International Monetary Fund). (2017). World Economic Outlook, October 2017: Seeking sustainable growth: Short-term recovery, long-term challenges.

[23] Jin, S., Yu, W., Jansen, H. G., \& Muraoka, R. (2012). The impact of irrigation on agricultural productivity: Evidence from India (No. 1007-2016-79777).

[24] Kanwar, S. (2006). Relative profitability, supply shifters and dynamic output response, in a developing economy. Journal of Policy modeling, 28(1), 67-88.

[25] Kumar, K. K. (2009). Climate sensitivity of Indian agriculture. Chennai: Madras School of Economics. 
Climatic and Non-climatic Influence on Food grains Production- Empirical Evidence from Indian Agriculture

[26] Kremers, J. J., Ericsson, N. R., \&Dolado, J. J. (1992). The power of cointegration tests. Oxford bulletin of economics and statistics, 54(3), 325-348.

[27] Krishnamurthy, C. K. B. (2012). The distributional impacts of climate change on Indian agriculture: A quantile regression approach (No. 2012-069).

[28] Kumar, K. (1998). Climate change impacts on Indian agriculture: results from a crop modeling approach. Measuring the impact of climate change on Indian agriculture.

[29] Kumar, A., \& Sharma, P. (2013). Impact of climate variation on agricultural productivity and food security in rural India (No. 2013-43). Economics Discussion Papers.

[30] Kumar, A. (2014). Climate change and sugarcane productivity in India: An econometric analysis. Journal of Social and Development Sciences, 5(2), 111-122.

[31] Kumar, A., Sharma, P., \& Joshi, S. (2016). Assessing the impacts of climate change on land productivity in Indian crop agriculture: An evidence from panel data analysis. Journal of Agricultural Science and Technology, 18(1), 1-13.

[32] Kumar, A., Ahmad, M. M., \& Sharma, P. (2017). Influence of climatic and non-climatic factors on sustainable food security in India: a statistical investigation. International Journal of Sustainable Agricultural Management and Informatics, 3(1), 1-30.

[33] Lahiri, A. K., \& Roy, P. (1985). Rainfall and supply-response: A study of rice in India. Journal of Development Economics, 18(2-3), 315-334.

[34] Mall, R. K., \& Aggarwal, P. K. (2002). Climate change and rice yields in diverse agroenvironments of India. I. Evaluation of impact assessment models. Climatic Change, 52(3), 315330 .

[35] Masters, G., Baker, P., \& Flood, J. (2010). Climate change and agricultural commodities. CABI Work Pap, 2, 1-38.

[36] Mendelsohn, R., Nordhaus, W. D., \& Shaw, D. (1994). The impact of global warming on agriculture: a Ricardian analysis. The American economic review, 753-771.

[37] Narayan, P. K. (2005). The saving and investment nexus for China: evidence from cointegration tests. Applied economics, 37(17), 1979-1990.

[38] Ouattara, B. (2004). Foreign aid and fiscal policy in Senegal (pp. 262-267). Manchester: Mimeo University of Manchester.

[39] Pathak, H., Ladha, J. K., Aggarwal, P. K., Peng, S., Das, S., Singh, Y., \& Aggarwal, H. P. (2003). Trends of climatic potential and on-farm yields of rice and wheat in the Indo-Gangetic Plains. Field Crops Research, 80(3), 223-234.

[40] Pathak, H., Aggarwal, P. K., \& Singh, S. D. (2012). Climate change impact, adaptation and mitigation in agriculture: methodology for assessment and applications. Indian Agricultural Research Institute, New Delhi, 1-302.

[41] Pesaran, M. H., \& Shin, Y. (1998). An autoregressive distributed-lag modelling approach to cointegration analysis. Econometric Society Monographs, 31, 371-413.

[42] Pesaran, M. H., Shin, Y., \& Smith, R. J. (2001). Bounds testing approaches to the analysis of level relationships. Journal of applied econometrics, 16(3), 289-326. 
[43] Rao, C. H. (2003). Reform agenda for agriculture. Economic and Political Weekly, 615-620.

[44] Sanghi, A., Mendelsohn, R., \& Dinar, A. (1998). The climate sensitivity of Indian agriculture. Measuring the impact of climate change on Indian agriculture, 69-139.

[45] Saseendran, S. A., Singh, K. K., Rathore, L. S., Singh, S. V., \& Sinha, S. K. (2000). Effects of climate change on rice production in the tropical humid climate of Kerala, India. Climatic Change, 44(4), 495-514.

[46] Singh, A. K. (2018). Influence of Climate and Non-Climatic Factors on Global Food Security Index: A Cross-Sectional Country-Wise Analysis. Socialsci Journal, 1(1), 22-35.

[47] Singh, A. K., \&Issac, J. (2018). Impact of climatic and non-climatic factors on sustainable livelihood security in Gujarat state of India: A statistical exploration. Agriculture and Food Sciences Research, 5(1), 30-46.

[48] Srivastava, A., Kumar, S. N., \& Aggarwal, P. K. (2010). Assessment on vulnerability of sorghum to climate change in India. Agriculture, ecosystems \& environment, 138(3-4), 160169.

[49] Sushila, K., \&Ghasi, R. (2009). Impact of global warming on production of jowar in India. Agricultural Situation in India, 66(5), 253-256.

[50] Tripathi, A., \& Prasad, A. R. (2009). Estimation of agricultural supply response by cointegration approach. The Indian Economic Journal, 57(1), 106-131.

[51] Vaidyanathan, A. (1987). Irrigation and agricultural growth. Indian Journal of Agricultural Economics, 42(902-2018-2591), 503-527.

[52] Virmani, A. (2008). Growth and poverty: policy implications for lagging states. Economic and Political Weekly, 54-62.

[53] Zhai, F., \& Zhuang, J. (2012). Agricultural impact of climate change: A general equilibrium analysis with special reference to Southeast Asia. Climate change in Asia and the Pacific: How can countries adapt, 17-35. 